\title{
Exploring young women’s perspectives of a targeted support programme for
}

teenage parents

Grant J. McGeechan, $\mathrm{PhD}^{\mathrm{a}^{*}}$, Michelle Baldwin MPH ${ }^{\mathrm{b}}$, Keith Allan, $\mathrm{PhD}^{\mathrm{b}, \mathrm{c}}$, Gillian O’Neill, MPH ${ }^{\mathrm{b}}$ and Dorothy Newbury-Birch, $\mathrm{PhD}^{\mathrm{a}}$.

a School of Health and Social Care, Teesside University, Middlesbrough, United Kingdom, TS1 3BX, g.mcgeechan@tees.ac.uk, 01642342331 - * corresponding author

b Child and Adult Service, Public Health, Durham County Council, Durham, United Kingdom

c Department of Public Health, NHS Borders, Melrose, TD6 9BD

Conflict of interest

The following authors are, or were employed by Durham County Council who commissioned this evaluation - Dr Keith Allen, Gillian O’Neill and Michelle Baldwin. 
Context: Teenage parents and their children are at risk of poorer outcomes than older mothers, and their peers.

Objective: Evaluate participants experiences of a targeted teenage parent support programme.

Design: A qualitative study was conducted to gain feedback from participants of a locally commissioned teenage parent support programme. Four focus groups were held with participants attending the programme in different areas of the county, and analysed using applied thematic analysis.

Participants: Teenage mothers aged 16-19 from vulnerable backgrounds $(n=18)$ attending a teenage parent support programme in County Durham.

Results: (1) Two major themes emerged from the analysis focussing on factors influencing enrolment and continued engagement and how the programme leads to personal development for mother and child. (2) The majority of participants felt that the group fostered a supportive environment and led to a reduction in social isolation. (3) The provision of free transport and childcare onsite was seen as a key component of the service without which many would not have been able to attend.

Discussion: (1) The programme appeared effective at increasing the emotional and social capabilities of teenage mothers. (2) It had a positive impact on parents' engagement in education and employment as well as impacting on children's social development.

Conclusions: (1) Targeted support programmes have the ability to increase social and emotional capabilities of teenage mothers and their children. (2) They can increase engagement in education and employment for teenage mothers. (3) The provision of transport, and free child care places can enhance engagement in such programmes. 


\section{Introduction}

Teenage pregnancy is described as a major health and social problem and has become a key policy area in most developed countries (1). Whilst there has been a $40 \%$ fall in teenage conception rates in England since 1998 for girls aged between 13 and 18, (from 46.6 per 1,000 population to 36.0 per 1,000) there are still around 50,000 conceptions a year in this age group (2), of which 75\% are unplanned (3), and 50\% end with an abortion (4). Within England there are large regional variations with the under 18-conception rate significantly higher in the North East (42.7 per 100,000) than for England as a whole (2).

A strong association exists between deprivation and teenage conception such that the likelihhod of becoming a teenage mother in the United Kingdom (UK) is almost 10 times higher for girls in the lowest socio-economic class than those in the highest (5) (6). Development of high levels of parental stress are more pronounced in teenage parents than in adult mothers (7) and teenage mothers are at a higher risk for development of mental health problems (8). Mothers with high parental stress have been found to have more negative parenting styles which is associated with poor behavioural, socio-emotional, cognitive outcomes, and coping in children therefore posing risks to a child's development (9).

Appropriate support mechanisms are therefore required which facilitate young parents in attaining a greater degree of social inclusion (10). A number of policies and initiatives have been developed in the UK which aim to tackle the causes and effects of social exclusion, such as an initiative based on recommendations from the Social Exclusion Unit (11) which aims to increase participation of teenage mothers in education, employment and training. However, this initiative was criticised due to limitations in the conceptualisation of social inclusion, and for being too focussed on deprivation whilst placing the responsibility for personal development on the parents themselves (12). 
Another initiative which was developed in the United States of America (US) is the Nurse Family Partnership (NFP) intervention which aims to improve outcomes for young mothers and their children (13), referred to as the Family Nurse Partnership (FNP) in the UK. FNP has been used in a number of countries and is recognised as a theory based preventive early childhood programme for vulnerable first time young mothers (14) (15) (16) (17). The programme involves intensive nurse home visiting which is designed to improve the health, well-being and self-sufficiency of first-time parents and their children. Research has demonstrated a range of positive outcomes following participation in FNP, such as improved parental health, fewer repeat pregnancies and improved school readiness and academic performance of children (16) (18). However, a recent trial of the FNP in England failed to replicate these results, although it must be noted that there are several differences between the US and UK variants of this intervention. Firstly, in the US context there is a lack of other offers of community support over and above the NFP, whereas there are several initiatives offered within the UK (11). Secondly recruitment to this trial differed from others in that it was open to all young mothers and not just those from lower socio-economic backgrounds (19) (20).

The primary aim of this study was to explore participants' experiences of a teenage parent support programme commissioned, and delivered by a local authority in the North East of England. This study formed part of a larger evaluation of a programme aimed at improving outcomes for those teenage parents who were furthest away from the employment market by increasing participation in employment, education, and training (21).

\section{Methods}

A qualitative approach was used to gain insight into the experiences of those participating in the teenage parent support programme within local communities in the North East of England. 
Focus groups were selected for this study as we were interested in exploring group dynamics and the shared experience of participants. This study was approved by the School of Health and Social Care ethics committee at Teesside University (063/15), approval was also granted by the local authority research governance committee.

\section{Intervention}

The programme ran one day per week for a period of 20 weeks, offering a holistic approach to identify support needs and maximise outcomes for teenage parents and their families delivered by staff within One Point Family Centres who are specifically trained to offer family support to parents with children under the age of five. The programme specifically focussed on social needs, education, employment and health and wellbeing with the opportunity to complete an accredited qualification element as a Youth Achievement Award. The service was specifically targeted at those who were not in a position to engage with a formal programme of learning or employment but would benefit from an opportunity to improve their resilience as well as their emotional and social capabilities. Parents were offered free transport to and from the group, and childcare was provided onsite to encourage participation. The service was structured so that half the day focussed on parental learning with the children in a crèche, with the second half involving children and parents and focussing on parenting skills. Whilst in the crèche children were supervised by appropriately trained staff and took part in activities designed to improve their social and emotional development in line with the early years framework (22).

\section{Patient and Public Involvement}

As an independent evaluation of an existing service, no participants were involved in the design, nor recruitment to the study. However, an executive summary of the study results were shared with the service providers and participants, whilst the final study report is in the public domain (21). 


\section{Participants}

The service providers acted as gatekeepers to this study by providing information sheets and invitation letters to all eligible participants who were taking part in a teenage parent programme in the locality. Whilst the teenage parent support programme was open to both mothers and fathers, those included in the evaluation were all women. A date and time was arranged for the focus group and potential participants were advised to attend on the day if they would like to take part. Participants were informed that participation was voluntary and they were free to withdraw at any time. Prior to the start of the focus group, participants were asked to sign a consent form. No financial incentive was offered to those who took part. For the most part participants for the focus groups were drawn from pre-existing teenage parent groups; however, for one of the focus groups participants were drawn from two separate groups within close proximity to each other.

\section{Data collection}

A semi-structured topic guide was prepared in advance of the focus groups which was designed to gain feedback on participants' experience of the group. Focus groups were conducted within the centre where the intervention had taken place and were facilitated by two researchers (GM and $\mathrm{MB})$.

Questions included asking participants how they became aware of the group, what sorts of activities they were involved in, and what impact, if any, the group had had on them and their children, as well as any impact on employment and education opportunities. 
Analysis

All focus groups were audio recorded and transcribed verbatim. Following this the transcripts were analysed using applied thematic analysis which is a phenomenological approach to qualitative analysis focussing on the experience of the participants $(23,24)$. Coding was approached inductively as we were interested in participants' experiences and were not coding in line with pre-existing theory. All names and identifiable information was removed prior to analysis. Focus groups were analysed by two researchers independently with any disagreements resolved by discussion $(25,26)$.

\section{Results}

Four focus groups were held with participants from teenage parent support groups throughout the local authority area between June 2015 and December 2016, with a total of 18 participants, all of whom were women (Mean $(M)=4.5)$. Focus groups lasted for between 22 and 37 minutes $(M=29.5)$.

Two major themes emerged from the analysis: Factors influencing enrolment and continued engagement in the programme; and the teenage parent support programme leading to personal development for mother and child, each with a number of sub-themes. The results are outlined below, with illustrative quotes provided in Table 1.

Factors Influencing enrolment and continued engagement in the programme

Pre-engagement work enhanced recruitment

It was clear that pre-engagement work conducted by the service providers helped them reach a number of young mums who otherwise may not have engaged with the service. Staff proactively recruited participants by running events before the start of the programme allowing 
potential participants to become familiar with the venue and the staff. Furthermore, service staff telephoned prospective participants to remind them of the service, and even knocked on the doors of people whom they felt would benefit from attending. Some participants attended the group because they knew someone who had previously experienced the service, whilst a few participants discussed being referred into the service by a health professional.

Participation in programme led to reduced social isolation

A majority of participants expressed that prior to enrolling in the teenage parent support programme they felt isolated from their peers and spent most of their time at home alone with their child. One of the reasons why participants continued to engage in the programme was the opportunity to interact and socialise with other young mums who understood what they were going through. Many of the participants formed close bonds with other young mums in their groups and they started to socialise with each other outside of the group. However, for some, as soon as the programme ended, the feelings of isolation returned as the group were no longer meeting either within or out with their group.

Free transport and childcare facilitates engagement

A central aspect of the teenage parent support programme was the provision of transport for participants to ensure that they could attend the group. Whilst a few participants had access to their own car, or lived close to the group, the vast majority relied upon this transport and would not have been able to attend had it not been provided for them. However, some participants did express concerns that following a change in transport provider the service was not as reliable as it had been. This resulted in some participants being late for group sessions as the taxi did not turn up on time, or missing sessions completely when they failed to arrive. 
Another central component to the teenage parent support group was the provision of an on-site crèche so that parents could bring their children along and involve them in the group. participants discussed that they would not have been able to engage in the programme without the crèche, as many of them had no access to childcare out with the group. Despite this, a number of issues were raised relating to the crèche staff. However, given that many of the participants had never left their children alone with anyone else before, it is perhaps not surprising that they found faults with the crèche service. By encouraging participants to raise any issues, service staff helped the participants to resolve these conflicts.

Teenage parent support programme leads to personal development for mother and child

Skill development can lead to future engagement in education and employment

A common theme which was discussed in the focus groups was how participation in the teenage parent support programme led to personal, and skill development which could lead to other opportunities in the future. Activities which were offered to participants varied from one group to the next however participants discussed taking part in sessions on financial advice, parenting skills, and youth achievement awards as well as more vocational activities such as cake decorating and jewellery making. Many participants went on to enrol in further programmes, or college, as well as finding employment following participation in the programme. This is something which they feel has only been possible because of the teen parent support programme and the encouragement they have received from the service staff.

Programme helps children develop social skills

In addition to providing development opportunities for teenage parents, it was felt that participation in the programme also led to development opportunities for children. By being a part of the programme and attending the crèche this provided some children with their first 
opportunity to interact with other children their own age. For some participants there was a noticeable change in the personality and behaviour of their children as the programme progressed. Furthermore, it became easier for them to leave their children in the crèche as they got used to letting other people look after them.

Service staff encourage participant development

An important aspect of the progression made by teenage parents who are enrolled on the programme is the support and encouragement offered by the staff who run the service. Most participants felt that they were well supported and could talk to the service staff about anything. As discussed above, when particular groups were concerned about the crèche staff they were encouraged to voice their concerns through the proper channels to ensure that the situation was handled responsibly and a solution could be found. This resulted in teenage parents and crèche staff sitting down and discussing issues which resulted in a more positive experience for all concerned going forward. Staff also encouraged participants to progress to other courses, or sign up for college, and offered advice and support to one participant who it was suspected may have dyslexia.

\section{Discussion}

Whilst the number of teenage pregnancies each year has been declining in England over the last few decades, the North East of England continues to have higher conception rates then the rest of the country (2). There has been growing interest in delivering services which encourage participation in education, training and employment within the UK, however these have been criticised for placing the responsibility of development on parents themselves (12), or for being ineffective (19). Therefore, there is a need for a holistic approach, focussing on the needs of 
first time parents and their children, for those who are furthest way for the employment market, which can improve their social and emotional capabilities

The results of this study also echoed findings from other UK studies which found that teenage mothers are at risk of social isolation (27). The group provided them with the opportunity to engage with peers who understand how difficult it can be to be a teenage parent. Furthermore, it also allowed children to interact with peers, some for the first time, which can be essential for healthy development (28). However, it is possible for participants to become socially isolated again once the group has finished, as few participants continued to socialise with each other after the course. The programme does include the planning of progression pathways to ensure that participants stay engaged with education or employment however perhaps more work needs to be done to ensure the opportunity to keep these individuals engaged is not missed.

A number of key factors helped to promote recruitment and continued engagement of teenage parents, with pre-engagement work seen as crucial in building up relationships with potential participants. Pre-engagement work is often the first step in getting people involved in treatment or an intervention and involves relationship building between the client and those delivering an intervention in order to develop a relationship (engagement) which will ultimately result in successful engagement in the service (contracting) (29). Research indicates that preengagement work is essential in recruiting hard to reach individuals into services and would be an essential component of any future services $(30,31)$.

lack of childcare and available transport would be a barrier to attendance and provision is likely to greatly enhance the likelihood of participation and likely to make it more inclusive Furthermore, the provision of onsite childcare, and transport to and from the venue can reduce barriers to attendance and provision is likely to make the service more inclusive. Whilst some 
issues arose with both of these components, participants felt empowered to speak out about it, encouraged by the service providers to voice their concerns, something which many would not have felt confident doing before taking part.

Similar to other studies, participants discussed how the staff running the programmes fostered a supportive environment and actively encouraged participants to go onto further education or employment (32). However, some aspects of the programme such as vocational skills training are likely to need to be uniquely tailored to groups depending on the interests of group members and availability of local facilitators. A number of participants applied to go to college, something they attributed to being encouraged by staff. There was also an emphasis on peer support with many participants encouraged to volunteer with subsequent groups to share their experiences. However, as some of our participants were amongst the first to take part in this programme they did not have the opportunity to receive peer support, but were asked as part of the programme to become peer supporters to those enrolling as part of the next cohort.

In summary the feedback received from participants of this programme was overwhelmingly positive. The majority of participants felt that the programme provided an opportunity for them to develop their parenting skills, and gave them the confidence to move onto education or employment. The programme also allowed their children to develop social skills by taking part in facilitated sessions with other children within the crèche setting. This was often the first time they had interacted with children their own age. The provision of childcare and transport to the service were seen as facilitators to engagement, and whilst there are cost implications for any local authority looking to run a similar service, many participants would not have attended without them. Furthermore, whilst not reported on within the focus groups the restrictive age of participants was found to be a barrier to recruitment and in subsequent cohorts the age range was extended to 24, provided the participant had at one stage been a teenage parent. 
To the best of our knowledge this is the first study looking at teenage mothers' experiences of being involved in a targeted support programme and provides evidence for its impact on the emotional and social development of mothers and their children.

\section{Key Messages}

- A holistic family-centred support programme, aimed at first time parents, and their children, can aid parental and child development.

- $\quad$ Pre-engagement work, free transport to and from groups, and free childcare can greatly enhance recruitment and retention of teenage parents.

- Supportive staff encouraged participants to progress onto further education or employment opportunities.

\section{Contributorship}

GJM contributed to the design and implementation of the evaluation and was involved in all aspects of data collection and analysis and drafting the manuscript.

MB contributed to the design and implementation of the evaluation, was involved in data collection and analysis and provided comments on the final manuscript.

KA contributed to the design of the evaluation and commented on analysis and the final manuscript.

GO contributed to the design of the evaluation and commented on the analysis and the final manuscript.

DNB contributed to the design of the evaluation and commented on the analysis and the final manuscript.

\section{Funding}


The authors would like to acknowledge support for this study by Durham County Council who funded it as part of a larger series of public health service evaluations.

\section{Competing Interests}

The following authors are, or were formerly employed by Durham County Council who funded this research: Michelle Baldwin, Keith Allan, Gillian O'Neill.

\section{Exclusive License}

I confirm this manuscript has not been accepted for publication elsewhere, is not being considered for publication elsewhere and does not duplicate material already published. I confirm all authors consent to publication of this manuscript. 
Table 1: Illustrative quotations

\begin{tabular}{|c|c|c|}
\hline Theme & Sub-theme & Illustrative Quotes \\
\hline $\begin{array}{l}\text { Factors influencing } \\
\text { enrolment and } \\
\text { continued engagement } \\
\text { in the programme }\end{array}$ & $\begin{array}{l}\text { Pre-engagement work } \\
\text { enhanced recruitment }\end{array}$ & $\begin{array}{l}\text { "I went to a Halloween one at (centre), but I knew about that through } \\
\text { the health visitor" FG1 P1 } \\
\text { "Mine was through me family worker" FG3 P2 } \\
\text { "Someone came knocking on me door... Asking us if I wanted to go" } \\
\text { FG4 P2 }\end{array}$ \\
\hline & $\begin{array}{l}\text { Participation in the } \\
\text { programme led to } \\
\text { reduced social isolation }\end{array}$ & $\begin{array}{l}\text { "When I had a baby, none of my friends were there as soon as she got } \\
\text { to a certain age they weren't bothered anymore and they weren't } \\
\text { interested. As soon as I started going to like these groups it was like } \\
\text { people to talk to. You feel like a normal person" FG1 P5 } \\
\text { "I say [name removed], I'm bored in the house, I'm coming for a coffee } \\
\text { or do you fancy coming.” FG3 P3 } \\
\text { "No, I live in, [place removed]... And it's in the middle of nowhere... } \\
\text { So it's like, there's one children's centre, but they don't have anything } \\
\text { on. (R - Do they not, so are you back to being stuck?) Aye” FG4 P1 }\end{array}$ \\
\hline
\end{tabular}




\begin{tabular}{|c|c|c|}
\hline & $\begin{array}{l}\text { Free transport and } \\
\text { childcare facilitate } \\
\text { engagement }\end{array}$ & $\begin{array}{l}\text { "But then it changed to volunteer drivers. And that's when we had the } \\
\text { problem. They were not showing up, and saying that they had shown } \\
\text { up." FG } 4 \text { P5 } \\
\text { "Mine's only like a bus away so it wasn't too bad for me" FG1 P4 } \\
\text { "Like, for me, my mam and dad work fulltime, so I've got no one. Only } \\
\text { my, like, he's got Godparents and that. He's got my friends. But none of } \\
\text { them will watch him." FG3 P1 } \\
\text { "It's like, one day after Christmas I was like please, please say you's } \\
\text { [sic] are going to be doing crèche when I come back" FG4 P4 }\end{array}$ \\
\hline $\begin{array}{l}\text { Teenage parent } \\
\text { support programme } \\
\text { leading to personal } \\
\text { development for } \\
\text { mother and child }\end{array}$ & $\begin{array}{l}\text { Skill development can } \\
\text { lead to future } \\
\text { engagement in education } \\
\text { and employment }\end{array}$ & $\begin{array}{l}\text { "I do that on a Thursday, I'm doing me level, NVQ2 now. But if I } \\
\text { wasn't, if I didn't go there [group], I would have had the, I don't know } \\
\text { a big word for that [R - Opportunity?] ... That's the one”. FG2 P2 } \\
\text { "Would like it if we did more stuff [to put] on our CV and more like } \\
\text { working experience and stuff, do you know what I mean?” FG3 P1 } \\
\text { "If it wasn't for [name] and [name] I don't think I would have started } \\
\text { College just yet” FG4 P2 }\end{array}$ \\
\hline
\end{tabular}


"We signed up for the volunteering service... Well, I did. But, and then that... We do all the level one in cake decorating, starting January, through the college" FG3 P2

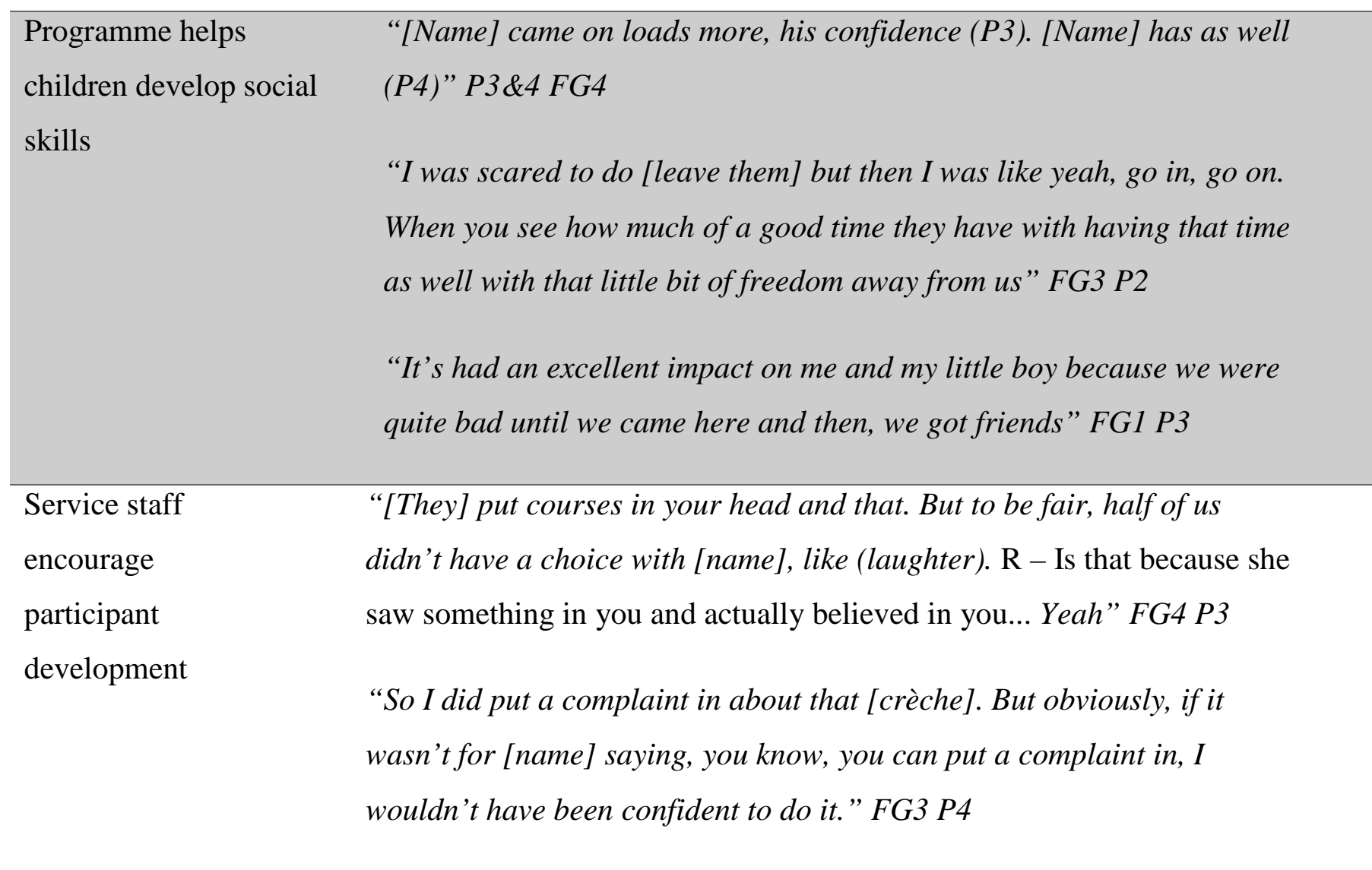




\section{References}

1. Shaw ME, Lawlor DA. Why we measure teenage pregnancy but do not count teenage mothers? Critical Public Health. 2007;17(4):311-6.

2. Office for National Statistics. Conception Statistics, England and Wales. 2017.

3. Dickins TE, Johns, S. E., \& Chipman, A. Teenage pregnancy in the United Kingdom: A behavioral ecological perspective. Journal of Social, Evolutionary, and Cultural Psychology. 2012;6(3):344.

4. Local Government Association. Tackling teenage pregnancy: Local government's new publich health role. In: Health a, social care and ageing, editor. London2013.

5. Conrad D. Deprivation-based inequalities in under-18 conception rates and the proportion of under-18 conceptions leading to abortion in England, 1998-2010. Journal of Public Health. 2012;34(4):609-14.

6. Bonell C, Maisey R, Speight S, Purdon S, Keogh P, Wollny I, et al. Randomized controlled trial of 'teens and toddlers': A teenage pregnancy prevention intervention combining youth development and voluntary service in a nursery. Journal of Adolescence. 2013;36(5):859-70.

7. Huang CY, Costeines J, Kaufman JS, Ayala C. Parenting stress, social support, and depression for ethnic minority adolescent mothers: Impact on child development. Journal of Child and Family Studies. 2014;23(2):255-62.

8. Lanzi RG, Bert SC, Jacobs BK. Depression among a sample of first-time adolescent and adult mothers. Journal of Child and Adolescent Psychiatric Nursing. 2009;22(4):194-202. 
9. Goodman SH, Brand SR. Infants of depressed mothers: Vulnerabilities, risk factors, and protective factors for the later development of psychopathology. In: Zeanah $\mathrm{CH}, \mathrm{Jr}$, editor. Handbook of infant mental health (3rd ed). New York, NY, US: Guilford Press; 2009. p. $153-70$.

10. McLeod A, Baker D, Black M. Investigating the nature of formal social support provision for young mothers in a city in the North West of England. Health \& Social Care in the Community. 2006;14(6):453-64.

11. Shaw M, Woolhead G. Supporting young mothers into education, employment and training: assessing progress towards the target. Health \& Social Care in the Community. 2006;14(2):177-84.

12. Kidger J. Including young mothers: Limitations to New Labour's strategy for supporting teenage parents. Critical Social Policy. 2004;24(3):291-311.

13. Olds DL, Henderson CR, Chamberlin R, Tatelbaum R. Preventing child abuse and neglect: a randomized trial of nurse home visitation. Pediatrics, 1986;78(1):65-78.

14. Department for Education. Parenting programmes In: Education Df, editor.: Department for Education 2011.

15. Coalition for Evidence Based Policy. Early Childhood Home Visitation Models: An Objective Summary of the Evidence About which are Effective. 2009.

16. Paulsell D, Avellar S, Sama Martin E, Del Grosso P. Home Visiting Evidence of Effectiveness Review: Executive Summary. O. In: Office of Planning RaE, Administration for Children and Families, editor. Washington: U.S. Department of Health and Human Services; 2010. 
17. Miles K. Using attachment theory in mentoring. Nursing times. 2011;107(38):23-5.

18. Olds D, Henderson CR, Jr., Cole R, Eckenrode J, Kitzman H, Luckey D, et al. Longterm effects of nurse home visitation on children's criminal and antisocial behavior: 15-year follow-up of a randomized controlled trial. Jama. 1998;280(14):1238-44.

19. Robling M, Bekkers MJ, Bell K, Butler CC, Cannings-John R, Channon S, et al. Effectiveness of a nurse-led intensive home-visitation programme for first-time teenage mothers (Building Blocks): a pragmatic randomised controlled trial. The Lancet,. 2016;387(10014)):146-55.

20. Olds D. Building evidence to improve maternal and child health. The Lancet. 2016;387(10014):105-7.

21. McGeechan GJ, Baldwin M, Allen K, Newbury-Birch D. A co-production evaluation of the County Durham Teenage Parent Support and Teenage Parent Apprenticeship Programme. 2017.

22. Tickell, C. (2011). The Early Years: Foundations for life, health and learning. An independent report on the early years foundation stage to Her Majesty's Government (media. education https://gov.uk/assets/files/pdf/F/The\%20Early\%20Years\%20Foundations\%20for\%20life\%20 health\%20and\%20learning.pdf

23. Guest G, MacQueen KM, Namey EE. Applied Thematic Analysis. Thousnad Oaks, CA: Sage; 2012.

24. Braun V, Clarke V. Using thematic analysis in Psychology. Qualitative Research Psychology. 2006;3(2):77-101. 
25. Trotter N, editor. Qualitative Research Methods. Public Health Research Methods. California: Sage; 2015.

26. Joffe H, Yardley L, editors. Content and thematic analysis. London: Sage; 2012.

27. Robling M, Bekkers MJ, Bell K, Butler CC, Cannings-John R, Channon S, et al. The Building Blocks Trial. Cardiff University; 2015.

28. Lin TJ, Justice LM, Paul N, Mashburn AJ. Peer interaction in rural preschool classrooms: Contributions of children's learning-related behaviors, language and literacy skills, and problem behaviors. Early Childhood Research Quarterly, 2016;37:106-17.

29. McManus, H. H., \& Thompson, S. J. Trauma among unaccompanied homeless youth: The integration of street culture into a model of intervention. Journal of aggression, maltreatment \& trauma, 2008;16(1):92-109.

30. Kauffman, K. S., Dosreis, S., Ross, M., Barnet, B., Onukwugha, E., \& Mullins, C. D. Engaging hard-to-reach patients in patient-centered outcomes research. Journal of comparative effectiveness research, 2013;2(3):313-324.

31. Newton, B., Speckesser, S., Nafilyan, V., Maguire, S., Devins, D., \& Bickerstaffe, T. (2014). The Youth Contract for 16-17 year olds not in education, employment or training evaluation. DFE-RR318A. London: Department for Education.

32. Channon S, Bekkers MJ, Sanders J, Cannings-John R, Robertson L, Bennert K, et al. Motivational interviewing competencies among UK family nurse partnership nurses: a process evaluation component of the building blocks trial. BMC nursing, 2016;15(1):55. 